\title{
Influence of culture media, temperature and light/darkness on the mycelial growth of Lasiodiplodia theobromae (Pat.)
}

\section{${ }^{1}$ Chukunda, F.A.; ${ }^{2}$ Onyeizu, U.R.}

\author{
${ }^{1}$ Department of Forestry and Environment, Faculty of Agriculture, Rivers State University of \\ Science and Technology, Port Harcourt, Nigeria. \\ ${ }^{2}$ Department of Environmental Management \& Toxicology, Michael Okpara University of \\ Agriculture, Umudike, Abia State, Nigeria
}

\section{$\begin{array}{ll}\text { ARTICLE INFO } & \text { ABSTRACT }\end{array}$}

Article No.: 031419046

Type: Research

DOI: 10.15580/GJAS.2019.1.031419046

Submitted: 14/03/2019

Accepted: $21 / 03 / 2019$

Published: 30/03/2019

*Corresponding Author

Chukunda, F.A.

E-mail: onyifrank2002@ yahoo.com

Phone: 08037501179

Keywords: Culture media, Potato

dextrose agar stem exudates

(PDASE), potato dextrose agar (PDA).
In this study, the effects of culture media, temperature and light and darkness on mycelial growth of $L$. theobromae were evaluated. Results of potato dextrose agar (PDA) and potato dextrose agar stem exudates (PDASE) were found suitable for mycelial growth of the $L$. theobromae. The fungus grew from 20-400C with optimum growth observed at 25-35oC on both media. On the 10th day, mycelial growth at 25-35oC was (15.6mm \pm $0.02-30.6 \mathrm{~mm} \pm 0.05 ; 18.4 \mathrm{~mm} \pm 0.28-32.5 \mathrm{~mm} \pm 0.10$ ) while mycelial growth recorded with PDASE was $(18.2 \mathrm{~mm} \pm 0.23-31.0 \mathrm{~mm} \pm 0.25 ; 22.8 \mathrm{~mm} \pm 0.02$ $-38.2 \mathrm{~mm} \pm 0.40$ ). There were no significant effects of light and darkness on the mycelial difference $(P \leq 0.05)$ on the growth of $L$. theobromae. It is recommended from this research work that amended potato dextrose agar (PDA) with stem exudates promoted the growth of test fungus $L$. theobromae and hence should be used as culture medium for fungi at $350 C$. 


\section{INTRODUCTION}

Lasiodiplodia theobromae (Pat.) is fungal pathogen of great economic importance. L. theobromae is an opportunistic plant pathogen that causes different types of plant diseases with worldwide distribution within tropical and subtropical regions (Faber et al., 2007). Its host range estimated to be more than 280 plant species (Domsch et al., 2007; Khanzada et al. 2006; Sutton, 1980 ) however, pathological effects varies among plants hosts.

In the tropics, $B$. theobromae is an economically important fungus known to cause major losses to mango, cocoa, banana and yam farmers (Rieger, 2006; Amuse et al., 2003). The fungus is known to cause tuber rots in yam, root rot in cassava, collar rot in peanuts, crown rot in banana, Stem end rot in mango fruits, stem rot in pawpaw and leaf spot in citrus (Sangeetha et al. 2011; Rossel et al., 2008; Khanzada et al., 2004b; Jiskani, 2002; Arjunan et al., 1999; Sangohote, 1988). B. theobromae is associated with die-back on mango (Khanzada et al., 2004a,b) and pod rot of cocoa (Phillips, 2007).

Onyenka et al., (2005) reported that the fungus is present in more than $70 \%$ of farms surveyed in Nigeria and it is linked to colossal yield losses around $80 \%$ of marco harvest. Jiskani (2002) and Sangchote (1988) respectively have identified $B$. theobromae to be a virulent fungus and a common isolate found on diseased mango fruits in Pakistan. French (2006) also reported that the pathogen infects and causes extensive damage to mango, cocoa, banana fruits and yam tubers. Rots caused by the fungus, particularly in the root and tuber crops often occur underground and so diagnosis of the disease is usually delayed or under repaired. Moreover, the wider host range (Crammer, 1979) and the host nonspecificity (Mohali et al., 2005) of $B$. theobromae makes control and management of the disease very difficult.

Regrettable there are limited information about the influence of culture media of Lasiodiplodia theobromae. The lack of information on host range of $L$. theobromae on the trees found in Aboretum of Forestry and Environment, Rivers State University, NkpoluOroworukwo, Port Harcourt has necessitated for this research. Therefore, the present study was undertaken to observe the influence of environmental factors on the mycelial growth of Lasiodiplodia theobromae.

This research is aimed at investigating the mycological studies on Lasiodiplodia theobromae the causal agent of gummosis infected African mahogany.

Specific objectives of this research were to:

(i) evaluate the effect of culture media on the mycelial growth of Lasiodiplodia theobromae.

(ii) determine effect of temperature on the mycelial growth of Lasiodipodia theobromae.

(iii) assess the effect of light and darkness on mycelial growth of Lasiodiplodia theobromae.

\section{MATERIALS AND METHODS}

\section{Study Area}

The study was carried out at the laboratory of Forestry and Environment (Pathology Unit) and Food Science and Technology, Rivers State University, Nkpolu Oroworukwo, Port Harcourt, Nigeria.

\section{Effect of Culture Media on the Growth of $L$. theobromae}

Effect of potato dextrose agar (PDA) and potato dextrose agar stem exudates (PDASE) media on the colony growth and sporulation of Lasiodiploda theobromae was evaluated. These media were poured into $9 \mathrm{~mm}$ diameter Petri dishes and allowed to solidify. $5 \mathrm{~mm}$ disc of the fungus was removed with a sterile cork borer from the edges of the fungus colony and placed in the centre of each $9 \mathrm{~mm}$ Petri dish containing the media. The Petri dishes were then wrapped with aluminum foil and incubated at room temperature $\left(28 \pm 2^{0} \mathrm{C}\right)$ in the dark for 5,10 and 15 days respectively. There were five replicate Petri dishes of each medium. The colony diameter in each Petri dish was measured after 5, 10 and 15 days respectively along two axes perpendicular to one another. (Ukoima and Chukunda, 2016; Chukunda, 2014; Saleem and Nasir, 1991).

\section{Effect of light and darkness on mycelial growth of fungus $L$. theobromae}

To study the effect of light and darkness on mycelial growth of isolated fungus $5 \mathrm{~mm}$ culture discs were cut with the sterilized cork borer from advancing margin of the colonies of $L$. theobromae and inoculated on PDA and PDASE plates separately at 5 days interval for 15 days. Carbon paper was used to wrap the Petri dishes for darkness, while unwrapped Petri dishes were used for light exposure. All the Petri dishes were incubated at $28 \pm 2{ }^{\circ} \mathrm{C}$ in five replicates under continuous light and darkness, (Kausar et al., 2009).

\section{Effect of Temperature on the Growth of Lasiodiplodia theobromae.}

Five millimeter culture disc of $L$. theobromae were cut with sterilized Cork borer from advancing margin colonies of the fungus and inoculated on PDA and PDASE plates separately. The effect of temperature on mycelial growth of $L$. theobromae was evaluated on potato dextrose agar (PDA) and potato dextrose agar stem exudates (PDASE). The inoculated plates were placed in an inoculating chamber and incubated at 15, $20,25,30,35^{\circ} \mathrm{C}$ in the dark. Each treatment was replicated three times. At each temperature the plates were arranged in a completely randomized design (CRD). Colony diameters were measured along two 
axes perpendicular to one another. The measurement of the mycelial growth was calculated after 5, 10 and 15 days of inoculation (Ukoima and Chukunda, 2016).

\section{Experimental Design and Statistical Analysis}

The experiment was laid out in a Completely Randomized Design (CRD). The treatment were replicated three time. Data collected were analyzed by analysis of variance (ANOVA) using SPSS Genstat software as described by Steel and Torrie (1980). Duncan Multiple Range Test at probability of $5 \%$ (DMRT) to separate the means.

\section{RESULTS}

Effect of culture media on mycelia growth of Lasiodiplodia theobromae

The results on the effect of culture media on the mycelial growth of $L$. theobromae are shown in Table 1 . The results indicated that potato dextrose agar (PDA) and Potato dextrose agar stem exudates (PDASE) significantly $(P \leq 0.05)$ affected the growth of Lasiodiplodia theobromae. PDA and PDASE affected the growth of $L$. theobromae at different days. On the $5^{\text {th }}$ days of incubation $L$. theobromae growth on both media was $(15.6 \mathrm{~mm} \pm 0.01 ; 18.2 \mathrm{~mm} \pm 0.02)$. However, the highest growth was observed on the $10^{\text {th }}$ day for both PDAE $(28.2 \mathrm{~mm} \pm 0.02)$ followed by PDA $(20.6 \mathrm{~mm} \pm$ $0.01)$.

Table 1: Effect of culture media on mycelia growth of Lasiodiplodia theobromae (Mean \pm SD)

\begin{tabular}{lccc}
\hline & \multicolumn{3}{c}{ Incubation period/mycelial growth $(\mathbf{m m}) /$ days } \\
\cline { 2 - 4 } Culture media & 5 & 10 & 15 \\
\hline PDA & $15.6 \pm 0.01^{\mathrm{D}}$ & $20.0 \pm 0.01^{\mathrm{D}}$ & $16.0 \pm 0.03^{\mathrm{b}}$ \\
PDASE & $18.2 \pm 0.02^{\mathrm{a}}$ & $28.3 \pm 0.02^{\mathrm{a}}$ & $20.5 \pm 0.04^{\mathrm{a}}$ \\
\hline
\end{tabular}

Mean \pm SD $(n=4)$ DMRT $(0.05)$

Effect of different temperature in the mycelial growth of Lasiodiplodia theobromae

The results on the effect of different temperatures on Lasiodiplodia theobromae mycelial growth are presented in Table 2. The result showed that different temperature and culture media influenced the mycelial growth of $L$. theobrommae. The relative increase in fungus mycelial growth increased with the increase in temperature. It was observed that the temperature range of $25-35^{\circ} \mathrm{C}$ was optimum for mycelial growth in both media (15.6 \pm $0.02 \mathrm{~mm}-30.6 \pm 0.05 \mathrm{~mm} ; 18.4 \pm 0.28 \mathrm{~mm}-32.5 \pm$ $0.10 \mathrm{~mm}$ ). Potato dextrose agar (PDASE), had the highest mycelial growth within the temperature range of $25-35^{\circ} \mathrm{C}(18.2 \pm 0.23 \mathrm{~mm}-31.0 \pm 0.25 \mathrm{~mm} ; 22.8 \pm$ $0.02 \mathrm{~mm}-38.2 \pm 0.40 \mathrm{~mm})$.

Table 2 Effect of Different Temperature on the mycelial Growth of Lasiodiplodia theobromae (Mean \pm SD) Temperature $\left(\mathrm{t}^{\mathrm{oC}}\right)$

Incubation period/mycelial growth $(\mathrm{mm}) /$ days

\begin{tabular}{ccccc} 
& \multicolumn{2}{c}{ PDA } & \multicolumn{2}{c}{ PDASE } \\
\hline 20 & $12.0 \pm 0.01^{\mathrm{a}}$ & $14.6 \pm 0.81^{\mathrm{e}}$ & $15.7 \pm 0.20^{\mathrm{a}}$ & $18.8 \pm 0.20^{\mathrm{a}}$ \\
25 & $15.6 \pm 0.02^{\mathrm{c}}$ & $18.4 \pm 0.28^{\mathrm{a}}$ & $18.2 \pm 0.23^{\mathrm{c}}$ & $22.8 \pm 0.20^{\mathrm{c}}$ \\
30 & $20.5 \pm 0.03^{\mathrm{b}}$ & $24.0 \pm 0.22^{\mathrm{b}}$ & $22.5 \pm 0.20^{\mathrm{b}}$ & $26.6 \pm 0.20^{\mathrm{b}}$ \\
35 & $30.6 \pm 0.05^{\mathrm{a}}$ & $32.5 \pm 0.10^{\mathrm{a}}$ & $31.0 \pm 0.25^{\mathrm{a}}$ & $38.2 \pm 0.40^{\mathrm{a}}$ \\
40 & $21.5 \pm 0.06^{\mathrm{b}}$ & $23.5 \pm 0.22^{\mathrm{c}}$ & $22.6 \pm 0.21^{\mathrm{b}}$ & $25.7 \pm 0.25^{\mathrm{b}}$
\end{tabular}

Mean \pm SD $(n=4) *$ PDA $=$ Potato dextrose agar, PDAE = Potato dextrose agar stem exudates, DRMT $(p<0.05)$

Effect of light and darkness on mycelial growth of Lasiodiplodia theobromae on potato dextrose agar (PDA) and potato dextrose agar stem exudates (PDASE) media incubated at room temperature $(28 \pm$ $\left.2^{\circ} \mathrm{C}\right)$

The result on the effect of light and darkness in Lasiodiplodia theobromae growth on stem bark tissues and leaves portions of Khaya grandifiolia are shown in Table 3. The result indicated that light and darkness significantly ( $p \leq 0.05$ ) affected the growth of $L$. theobromae at different days. On the $5^{\text {th }}$ day of incubation, L. theobromae under continuous darkness mycelial growth on PDA and PDASE was (13.5 \pm $0.20 \mathrm{~mm}-18.2 \pm 0.8 \mathrm{~mm})$. In continuous light, $L$. theobromae mycelial growth was $(12.3 \pm 0.02 \mathrm{~mm}-16.0$ 
$\pm 07 \mathrm{~mm})$. Generally, the highest growth was observed after 10 days for light and darkness on both media (16.8 $\pm 0.22 \mathrm{~mm}-28.1 \pm 0.22 \mathrm{~mm}$ ) for continuous light while continuous darkness was $(25 \pm 0.30 \mathrm{~mm}-30.5 \pm$ $0.31 \mathrm{~mm})$.

Table 3: Effect of light and darkness on mycelial Growth of Lasiodiplodia theobromae on PDA and PDASE media incubated at room temperature $28 \pm 2{ }^{\circ} \mathrm{C}$ (Mean \pm SD)

\begin{tabular}{|c|c|c|c|c|}
\hline \multirow[t]{3}{*}{ Light/darkness } & \multicolumn{4}{|c|}{ Incubation period/mycelial growth $(\mathrm{mm}) /$ days } \\
\hline & \multicolumn{2}{|c|}{ PDA } & \multicolumn{2}{|c|}{ PDASE } \\
\hline & 5 & 10 & 5 & 10 \\
\hline Continuous light & $12.3 \pm 0.02^{b}$ & $16.8 \pm 0.22^{b}$ & $16.0 \pm 0.70^{\circ}$ & $25.1 \pm 0.22^{\mathrm{a}}$ \\
\hline Continuous darkness & $13.5 \pm 0.20^{\mathrm{a}}$ & $18 \pm 0.30^{\mathrm{a}}$ & $18.2 \pm 0.81^{\mathrm{a}}$ & $26.5 \pm 0.31^{a}$ \\
\hline
\end{tabular}

\section{DISCUSSION}

The mycelia growth of Lasiodiplodia theobromae (Table 1) were significantly affected by the culture media of potato dextrose agar (PDA) and potato dextrose agar stem exudates (PDASE). The results indicated that there was significant interaction between type of medium and mycelia growth of $L$. theobromae. The present research findings agreed with the reports of Alam et al., (2001) who recorded good mycelium growth of Botryodiplodia theobromae on potato dextrose agar (PDA) than on potato dextrose agar stem exudutes (PDASE). Similarly, Qureshi and Meah (1991), observed linear growth of $B$. theobromae on Richard agar solution, mango leaf extract agar on PDA. Alasoadura (1969) observed maximum stromata of $B$. theobromae on malt agar and oat meal agar. Sabalpara et al., (1991) reported that nutrient rich medium supported the size and number of pycndia produced by $B$. theobromae. Saha et al., (2008) and Jash et al., (2003) reported on the influence of culture media and environmental factors on mycelial growth and sporulation of Lasiodiplodia theobromae: in their findings addition of root extract increased sporulation and mycelial growth of $L$. theobromae which was in agreement to our findings. Several other researchers stated that PDA was the best media for mycelial growth (Xu et al., 1984).

Alam et al., (2001) reported that highest mycelial growth and sporulation of $B$. theobromae was recorded on PDA, which was in agreement to the present work. Several other researchers also stated that PDA was the best media for mycelial growth (Xu et al., 1984; Maheshwari et al., 1999). Kumar and Singh (2000) also stated that $L$. theobromae grew well in potato dextrose medium. Result of this study agrees with that of Karlatti and Hiremath (1989), who observed high mycelial growth of Altermaria zinniae on potato dextrose agar medium and recorded higher sporulation on leaf extract dextrose agar medium.

The mycelia growth of lasiodiplodia theobromae (Table 3) showed a variable trend in response to temperature change using potato dextrose agar (PDA) and potato dextrose stem exudates (PDASE) media used. mycelia growth increased as temperature increased from $20-35^{\circ} \mathrm{C}$ and then decreased with further increase temperature. However, optimum mycelia growth of test fungus occurred at $25-35^{\circ} \mathrm{C}$. This results agreed with those reported by Quroshi and Meah (1991) and Alam et al., (2001) who reported that $25-30^{\circ} \mathrm{C}$ temperatures was optimum for the colony growth and sporulation of lasiodiplodia theobromae.

However, fungi grow on diverse habitants in nature and ark cosmopolitan in distribution requiring several specifics element for growth and reproduction. A wide range of media are used for isolation of different fungi and colony morphology (Kuhn and Ghannoun 2003; Kumara and Rawal, 2008). Observed that culture media influenced the growth and sporulation of some indian isolates of Colletotrichum gloeosporides. Similarly, Kuhn and Ghonnoum (2003) reported that a wide range of media are used for isolation of different groups of fungi that influence the vegetative growth and colony, morphology, pigmentation and sporulation depending upon the composition of specific culture medium. Ray (2004) showed that lactose and glucose had similar effect on growth of $L$. theobromae. Jash et al., (2003) also, observed that sucrose was the best carbon source for growth of Altemaria zinnia followed by starch and maltose, mannitol produced the least growth.

The results of the effects of light and darkness on fungal growth (Table 3 ) revealed that there was an increase in growth of $L$. theobromae in both light and darkness. Rewal and Grewal (1989) studied the effect of light on conidial germination of three strains of Botrytis cinerea infecting chickpea, and found that conidia of $B$. theobromae germinated best under continuous light and strain $B_{2}, B$. theobromae of germinated well under light and darkness treatment. From the study, it implied that light and darkness are necessary for growth and sporulation of test fungi. This is in agreement with Ahmed (1985) who observed that light promoted the growth and sporulation of Collectotrichum gloeosporoides.

Similarly, Marshi et al., (1959) reported that fungi exhibited varying response to light depending on the light intensity, quality and duration of exposure. Prota 
(1992), Oladiran and Iwu (1993) and Pihet et al., (2009) reported that ultra violet (UV) radiation or sunlight affected the survival of fungal spores, sclerotia and pycndia. However, some fungi need light to sporulate whereas other fungi sporulate better in darkness. In their investigation, Aspergillus ornatus produced abundant conidia when grown in continuous light and virtually none when grown in dark while cleistothecia and ascospores are produced in the dark whereas neither is produced in continuous light (Schwemmin, 1960).

Hill (1976) further explained that light inhibits glucose uptake and phosphorylation which caused starvation and retards fungi growth and conidia formation. Conversely the growth of Mycospharella pinodes, Aspergillus niger increased when exposed to darkness.

On the contrary, Alam et al., (2001) reported that light is not necessary for growth and sporulation of $B$. theobromae, but it enhances the growth and the number of conidia formation which is in partial agreement with the observation of Rewal and Grewal (1989). However, the increasing glucose in medium, may have cause the fungus to utilize it in a certain level and grow properly, and after that level, the fungal physiology does not permit the utilization of glucose for the growth of the pathogen. The fungus might utilize the glucose by different ways instead of growth and formed more pigmentation using more glucose (Teyegaga and Clerk 1972). According to Cochrane (1958), temperature range permitting reproduction is usually narrower than that permitting growth. Earlier, Leach (1979) had reported variations in optimum temperature requirements within the same species for light induced sporulation at continuous light and continuous darkness. Alam et al., (2001) obtained more growth of $L$. theobromae under continuous light and less in continuous darkness. These findings agreed with the present research work where $L$. theobromae test fungi had a good growth performance for both light and darkness. However, Teygaga and Clerk (1972) earlier demonstrated the relationship between Cercospora canescens conidia longevity and storage humidity, and observed that in the dark there was longest survival of conidia at low humidity than those under light. Generally the spores stored in the darkness appeared to be more viable than those in light. This may be due to metabolic disruption by light or that light inhibited the spores of test fungi thus reducing their percentage conidial germination.

\section{CONCLUSION AND RECOMMENDATIONS}

\section{Conclusion}

Our findings revealed that culture media differently influenced the growth, colony character and sporulation of the test fungi in the two test media employed in the present study, potato dextrose agar stem exudate (PDASE) was found to be most suitable for mycelial growth while potato dextrose agar PDA produced most visible colony morphology. It is concluded that instead of using single culture medium, a combination of two or more media will be more appropriate for routine cultural and morphological characterization.

\section{Recommendations}

Based on the present findings the following recommendations are made;

1. From the study potato dextrose agar stem exudates was found to be good medium of growth that supported the growth of $L$. theobromae.

2. It is revealed from the study that temperature, light and darkness significantly $(P \leq 0.05)$ affected the mycelial growth of $L$. theobromae.

\section{RFERENCES}

Alam, S.M., Most-Ferdousi, B., Montaz, A.S., Rafiqul Islam, M. \& Shah-Alam-M (2001). Effect of Temperature, Light and Media on growth, sporulation, formation of pigments and Pycnidia of Botryodiplodia theobromae Pat. Pakistan Journal of Biological Science, 4 (10): 1224-1227.

Chukunda, F. A (2014). Post-harvest fungal diseases of Persea gratissima (C.F. Gaerth) and Dacryodes edulis (G.Don) H.J. Lam, Fruits. Rivers State, University of Science and Technology, Ph.D Rivers State, Nigeria, 21.

Cochrane, V. W (1958). Physiology of fungal. John Wiley \& Sons, Inc. New York, 524.

Crammer, J (1979). Botryodipiodia theobromae. Commonwealth Mycological Institute, Kew, Surrey. 123.

Domsch, K.H, Gams, W. \& Anderson, T.H. (2007). Compendium of Soil Fungi. 2 (ed). Cornell University, England.

French, B. R (2006). Diseases of food plants in Papua New Guinea- A compendium. 38.

Jash, S., Dutta, S. Bandyopadhyay S. \&. Laha (2003). Effect of different culture media, $\mathrm{pH}$ and carbon sources on growth and sporulation of Anemaria zinniae Pape causing leaf and flower blight of marigold. Environmental Ecology, 21, 321-325.

Jiskani M.M. (2002). Dying of mango orchards needs special attention, Sindh Agriculture University, Pakistan.

Kartatti, R. S. \& Hiremath, P. C. (1989). Cultural and growth characteristics of Alternada zinniae, causal agent of leaf and inflorescence blight of mangold. Mysore Journal Agricultural Science, 23, 487489.

Khanzada, M. A., Rajput, Q.A \& Shahzad S (2006). Effect of medium, temperature, light and inorganic fertilizers on In vitro growth and sporulation of Lasiodiplodia theobromae isolated from mango. Pakistan Journal of Science, 38(3):885-889. 
Khanzada, M.A, Lodhi, A.M \& Shahnd S. (2004a). Mango dieback and gummosis in Sindh. Pakistan caused by Lasiodiplodia theobromae. Plant Health Progress.

Khanzada, M.A, Lodhi, A.M \& Shahnd S. (2004b). Pathogenicity of Lasiodiplodia theobromae and Fusatium solani on mango. Pakistan Journal of Science, 36(1):181-189.

Kuhn, D. D. \& Ghonnoum, M. A (2003). Indoor mold, toxigenic fungi, and starchy Botrys chartarum: Infectious disease perspective. Clinical Microbiology Review, 16 (1): 144-172.

Kumar P.S. and Singh S.R (2000). First report of Lasiodiplodia thecbromae as a foliar pathogen of Padhenkni hysterophorus. Plant Disease, 84, 1343.

Kumara K. L W \& Rawal R. D (2008). Influence of carbon, nitrogen, temperature and $\mathrm{pH}$ on the growth and sporulation of some Indian isolates of Colletotrichum gloeosporioides causing anthracnose disease of papaya (Carrica papaya L.) Tropical Agricultural Research Extension, 11:7-12.

Maheswari, S. K., Singh D. V. \& Sahu A.K. (1999). Effect of several nutrient media, $\mathrm{pH}$ and carbon sources on growth and sporulation of Altemaria altemata. Journal of Mycopathology Research, 37, 21-23.

Mohali, S. Burgess, T.I \& Winglleld, M. J. (2005). Diversity and host association of the tropical Tree endophyte Lasiodiplodia theobromae revealing using simple sequence repeat markers, Berlin Forest Pathology, 35:385-396.

Oladiran, A. O. \& Iwu, L. N (1993). Studies on fungi associated with tomato fruit rots and effect of environmental factors on storage. Mycologia, 21:157163.

Onyenka, T.J, Dixon, A.G.O \& Ekpo, E.J.A. (2005). Identification of levels of resistance to cassava root rot disease (Bohyaiipmdia theobromae) in Africa landrace and improved germplasm using in-vitro inoculation methods. Euphytica 1457(3), Netherlands, Springer. 281-288.

Phillips A.J.L (2007). Lasiodiplodia theobromae Portugal Centro de Recursos Microbiobgicos, Faculdade de
Ciênciase Tecnologia, Universidade Nova de Lisboa, 2.

Rawal, N. \& Grewel, J. S (1989). Effect of temperature, light and relative humidity on conidial germination of three stains of Botrytis cinerea infecting chickpea Indian Phytopathology 42: 79-83.

Ray, R. C (2004). Extracellular amylase (production by fungi) Botryodipiodia theobromae and Rhizopus oryzae grown on cassava starch residue. Journal of Environmental Biology, 25, 489495.

Rieger M (2006). Introduction to fruit crops. The Haworth Press. NewYork, 87.

Saleem A \& Nasir, M. A. (1991). Culture Media Directorate of Agricultural Information, Agriculture Department, Government of the Punjab, Lahore.

Sangchote, S (1988). Botryodiplodia stem end rot of mango and its control. Kasetsart Journal of Natural Science Supply, 22:67-70.

Sangeetha, G. Anandan A, Rani S. U (2011). Morphological and Molecular characterization of Lasiodiplodia theobromae from various banana cultivars causing crown rot disease in fruits. Archives of Phytopathology and Plant protection, 1-12.

Schwemmin, D. J (1960). Light controlled reproductive differentiation in Aspergillus ornatus. University of Michigan, U.S.A.

Steel, R. G. D \& Torrie J. H. (1980). Principles and Procedures of Statistics: A Biometrical Approach. $2^{\text {nd }}$ edition. 597. McGraw Hill Book Company, New York.

Sutton, B.C. (1980). The Coelomycetes Common wealth Mycological Institute. Kew, Surrey.

Teyegaga, A. \& Clerk, G. C (1972). Germination and survival of conidia of Cercospora caneslens. Tropical Agriculture, 6: 197-204.

Ukoima H. N. and Chukunda, F. A (2016). Influence of physiological factors on mycelial growth of Botryodiplodin theobromae Pat., isolated from Annona muricata. Nigerian Journal of Oil and Gas Technology, 1 (1): 39-50.

Xu, S.O., Yuan, S.Z. \& Chen X. C. (1984). Studies on pathogenic fungus (Allernada tennrris Nees) of poplar leaf blight. Journal of North East Forestry Institution, $12,56-64$. 